\title{
Monetary and Fiscal Policies Interaction in a Large Emerging Economy: Which Is the Leader Policy?
}

\author{
Ricardo Ramalhete Moreira ${ }^{1} \&$ Edson Zambon Monte $^{2}$ \\ ${ }^{1}$ Department of Economics, Research Group in Econometrics (GPE), CNPq's Researcher, Federal University of \\ Espírito Santo (UFES), Vitória, Espírito Santo, Brazil \\ ${ }^{2}$ Department of Economics, Research Group in Econometrics (GPE), Federal University of Espírito Santo \\ (UFES), Vitória, Espírito Santo, Brazil \\ Correspondence: Ricardo Ramalhete Moreira, Av. Fernando Ferrari, 514, Goiabeiras | Vitória - ES - CEP \\ 29075-910, Brazil.
}

Received: September 14, 2021

Accepted: October 20, 2021

Online Published: October 22, 2021

doi:10.5539/ijef.v13n11p81

URL: https://doi.org/10.5539/ijef.v13n11p81

\begin{abstract}
This article analyzed the intertemporal interaction between monetary and fiscal policies in Brazil. We aimed at identifying if structural innovations to the real interest rate were able to induce unexpected effects on fiscal and inflation dynamics. To do so, we estimated Structural Vector Autoregressive (SVAR) models over the period from Jan/2004 to Apr/2019. Moreover, we filtered out the time series' long-memory component through a fractional integration approach, so that we did not build our analysis on traditional unit root tests. The findings showed that monetary policy shocks robustly activated an unconventional transmission channel based on the Fiscal Theory of the Price Level, i.e., an unexpected and induced change in primary surpluses, through a wealth effect, as mechanism to satisfy the Government's intertemporal budget constraint. Such a result is strongly linked to another evidence, that is, the monetary policy`s role as a leader in shaping inflation over time.
\end{abstract}

Keywords: fiscal policy, monetary policy, fiscal theory, SVAR, fractional integration, Brazil

JEL: E43; E52; E62.

\section{Introduction}

Over the last decades, several studies have focused on the role of the coordination between monetary and fiscal policies as potentially influencing both their effectiveness and credibility. The literature on rules applied to monetary policy has strongly developed since the seminal contributions of Kydland and Prescott (1977). Nowadays, it is almost consensual the idea of better long-term results for the macroeconomic performance as a consequence of autonomous and independent central banks. Monetary policy rules have emerged in distinguished forms, but a common feature is the core importance of credible announcements and time-consistent basic interest rate adjustments as instruments for shaping a stable and low inflation rate over years and decades.

On the other hand, fiscal policy has also received increasingly attention by the applied literature as aspects linked to fiscal reputation, credibility and public debt management have become daily and practical attributes of governments both in developed and developing countries. In such a view, the basic premise is that fiscal policy faces an intertemporal budget constraint, and that primary surpluses should be managed to satisfy the former over time. Thus, fiscal rules have been proposed in a specific manner so as to allowing public debt stabilization and solvency.

Viewed in divided dimensions, one may interpret each of those macroeconomic policy as having an independent and even exogenous dynamics in relation to the other. However, there has been an increasing concern with potential specific effects and externalities depending on the current dominance regime. One example of this concern is found in the works of Woodford (2001), Cochrane (1998) and Leeper (1991), which together gave origin to the Fiscal Theory of the Price Level (FTPL). In a broad sense, such a theory establishes the role of coordination between monetary and fiscal policies in order to determine: i) if a country is really able to control inflation rates; ii) how a potential climbing public debt would be reverted under an active and pro-cyclical fiscal policy (i.e., a non-ricardian structure); iii) the limits to the effectiveness of an autonomous and active monetary policy if the fiscal dimension is not committed to counter-cyclical rules. 
To assess this subject, we can thus test for the existence of monetary or fiscal dominance regimes, which was originally developed by Sargent and Wallace (1981). While the former type is marked by an autonomous and low-inflation committed monetary policy besides a counter-cyclical fiscal one; the latter is formed by a passive monetary policy and a pro-cyclical fiscal management. Monetary dominance is associated with basic interest rates leading the macroeconomic stabilization and the fiscal adherence to the intertemporal budget constraint over time. In turn, fiscal dominance is associated with the lack of autonomy and effectiveness of the monetary policy, as well as the continuous deterioration of public debt conditions. Perhaps the stronger lesson from this literature is that an independent and low inflation committed monetary policy is not an enough condition for macroeconomic stability in long-term. The fiscal contribution to this goal is another necessary pillar.

In this work we aimed at analyzing the intertemporal interaction between monetary and fiscal policies in Brazil, thereby seeking to identify if one of these became a leader to drive the other one. In such a sense, we contributed to previous works applied to Brazil, such as Fialho and Portugal (2005), Moreira et al. (2007), Gadelha and Divino (2008) and Nobrega et al. (2020), among others.

In our study, we estimated a small-scale Structural Vector Autoregressive (SVAR) model, over the period from January 2004 to April 2019. Moreover, unlike the most part of the related literature, we firstly filtered out the time series' long-memory through the fractional integration approach (Geweke and Porter-Hudak, 1983; Baillie et al. 1996), instead of building our further estimation on conventional unit root tests. The main findings showed that monetary policy was a leader to shape inflation, as well as to inducing better primary surpluses management in Brazil. This latter and unconventional result can be explained by a particular mechanism which is consistent with the FTPL.

The remainder of this article is structured in the following way: in section 2, we made some comments on the theoretical aspects related to monetary and fiscal dominance regimes; section 3, in turn, described the evidence reported by related and empirical studies applied to Brazil; in section 4, we explained the methodological strategy of this work, as well as the dataset; at last, in section 5, we showed and analyzed the empirical results.

\section{Theoretical Aspects}

One of the first attempts to formalize the concept of dominance between fiscal and monetary policies was Sargent and Wallace (1981). Until the beginning of the 80`s, macroeconomic theories were deeply influenced by the Ricardian Equivalence theory, in which public debt changes would not be accompanied by pressures on inflation rates and so there would not be any effect on the effectiveness of monetary instruments. Sargent and Wallace (op. cit.), on the other hand, argued that a persistent and unbalanced fiscal policy, followed by a continuous public debt growth, could cause effects on inflationary expectations, as households and firms would expect the Central Bank to issue new money to cover fiscal deficits in the future. Thus, current inflation rates would be increased in anticipation, even though the Central Bank was committed to maintaining inflation stability over time. This was the first concept of fiscal dominance in modern macroeconomics. In such a context of a non-ricardian regime, a tighter monetary policy can induce an increment of the expected inflation, thereby leading the economy to the so-called unpleasant monetarist arithmetic.

However, the most general approach to deal with dominance regimes between monetary and fiscal policy came by the contribution of the Fiscal Theory of the Price Level (Woodford, 2001; Cochrane, 1998; Leeper, 1991). It is a general approach because it allows for different dominance regimes: monetary dominance, fiscal dominance and a non-dominance regime, in which neither fiscal policy nor monetary policy perform a leadership on each other. We can assess these three possible scenarios by means of a simple formalization for the government's intertemporal budget constraint, like in equation.

$$
\frac{d e b t_{t}}{p_{t}}=p s_{t}+\sum_{i=1}^{n} \beta^{i} E_{t}\left[p s_{t+i}\right]+m_{t}+\sum_{i=1}^{n} \beta^{i} E_{t}\left[m_{t+i}\right]+\varepsilon_{t}
$$

It establishes that the public debt in real terms $\left(\frac{d e b t_{t}}{p_{t}}\right)$, given $d e b t_{t}$ the nominal public debt and $p_{t}$ the general prices level, should be equal to the present value of a sum for the current primary surpluses $\left(p s_{t}\right)$, expected future primary surpluses $\left(\sum_{i=1}^{n} \beta^{i} E_{t}\left[p s_{t+i}\right]\right)$, seigniorage revenues $\left(m_{t}\right)$ and expected future seigniorage revenues $\left(\sum_{i=1}^{n} \beta^{i} E_{t}\left[m_{t+i}\right]\right) ; \beta^{i}$ stands for the discount factor $(\beta<1), E_{t}$ for the expectation operator and $\varepsilon_{t}$ for a white-noise stochastic shock.

In a monetary dominance regime, we find the classic ricardian corollary, i.e., a fiscal deficit covered by a rise in public debt has no effect on output dynamics and so there is no inflationary pressures. It occurs because the public 
rationally anticipates that the government will soar primary surpluses in the future so as to satisfy its intertemporal budget constraint. Thus, any increase of current disposable income will be converted into private savings and then it prevents an output effect. In this regime, fiscal policy is the passive policy, and it satisfies the government's intertemporal budget constraint; while monetary policy is the active one (using the terminology of Leeper, 1991) as it is committed to inflation control over time. In terms of equation (1), when $p s_{t}$ decreases and $\frac{d e b t_{t}}{p_{t}}$ is rising, there exists an expectation for climbing primary surpluses $\left(\sum_{i=1}^{n} \beta^{i} E_{t}\left[p s_{t+i}\right]\right)$ in the future, as the fiscal policy adjusts itself to the intertemporal budget constraint. In turn, the Central Bank is attached to an inflation target, so that $m_{t}$ and $\sum_{i=1}^{n} \beta^{i} E_{t}\left[m_{t+i}\right]$ do not adjust endogenously to fiscal requirements.

In turn, with a fiscal dominance state we do not find a passive fiscal policy, but an active one. Primary surpluses follow a random walk, which is determined by idiosyncrasies and political goals. Therefore, primary surpluses do not satisfy the government's intertemporal budget constraint. A lower current primary surplus $s p_{t}$ can be followed by lower expected primary deficits in the future $\left(\sum_{i=1}^{n} \beta^{i} E_{t}\left[p s_{t+i}\right]\right)$, as the public do not believe in a turnaround of the fiscal dynamics ahead. If the monetary policy becomes a passive policy, we have so the fiscal dominance scenario: an augmentation of the public debt is accompanied by a stimulative monetary policy, either by rising money supply conditions $\left(m_{t}\right.$ and/or $\left.\sum_{i=1}^{n} \beta^{i} E_{t}\left[m_{t+i}\right]\right)$, or by cutting the basic interest rate in order to reduce the government's financial expenditures with its bonds and debt.

It is noteworthy that the basic interest rate performs a role in determining the discount factor $\beta^{i}$. Although it is mainly dependent on the interest rates' long-term structure, the short-term interest rate, which is ruled by the Central Bank, also has an effect on such a factor. So, when the Central Bank, for instance, lower the basic interest rate there exists an increase in $\beta^{i}$, i.e., the flow of expected future outcomes receive a higher present value. The fiscal dominance regime is an inflationary context in a classical manner, as the rise in inflation comes from a monetary accommodation. In other words, the government's intertemporal budget constraint is satisfied by seigniorage revenues or by lowering the basic interest rate and consequently the public debt growth rate.

However, the FTPL does not require the fiscal dominance regime as an assumption for inflation becoming sensitive to fiscal disequilibria. It can occur under a non-dominance regime: both monetary policy and fiscal policies are active, thereby being not constrained to the government's intertemporal budget.

Under this particular regime, the inflation rate can be affected by a wealth effect, even if the Central Bank keeps its monetary instruments in consistency with inflation stability in long-term. It assumes that a growth of the public debt, which is not followed by a counter-cyclical fiscal reaction, does not imply a default risk in short-term. The transversality condition is not a necessary condition in the FTPL (Woodford, 2001). Therefore, the public continues to hold public bonds and so financing the fiscal deficits. As a consequence, households regard an increase of the real public debt as an expansion in private savings, so that it induces higher private consumption and also output levels. The resulting surging inflation rate then can be explained by a new-keynesian Phillips Curve mechanism.

An unconventional transmission mechanism is crucial to understand our main empirical finding in this study. If we assume that inflation rates do not present expressive rigidity in short-term, thereby being sensitive to the real interest rate adjustment, and, at the same time, the primary surplus is marked by an exogeneity regarding public debt changes, then an increment of the real interest rate can stimulate a rise in primary surpluses in short-term. It occurs because the resulting decline in inflation rate causes a soaring real public debt. In turn, as current and future expected primary surpluses do not react to the public debt dynamics (which is rising), the aforementioned wealth effect is activated, so that the consequent enlargement in consumption and output is accompanied by an augmentation of the current primary surplus through tax revenues.

The FTPL brought into the macroeconomic debate an important aspect of monetary and fiscal policy coordination. It stressed the idea according to which even the most committed Central Bank to an inflation target can have to deal with a loss of monetary policy's effectiveness and credibility if the fiscal authority does not respond to long-term solvency goals and budget restrictions.

\section{Empirical Evidence: A Brief Review}

Regarding available empirical studies for dominance regimes in Brazil, the findings are not convergent. The first related work is Fialho and Portugal (2005), which covered the period from January 1995 to September 2003. They assumed the existence of a main relation between the public debt to GDP ratio and the primary surplus to 
GDP ratio. Such an analysis was performed by a Vector Autoregressive (VAR) approach and its impulse response functions. Overall, Fialho and Portugal (op. cit.) achieved results in favor of a monetary dominance regime in the Brazilian economy, which was marked by an active monetary policy, thus diverging from the non-ricardian policies of the TFLP.

In turn, Moreira et al. (2007) developed an optimal monetary policy rule, taking into account fiscal disequilibria, in order to evaluate if Brazil presented active or passive fiscal and monetary policies over the quarterly period from 1995/01 to 2006/02. The study found that fiscal deficits statistically affected the inflation rate by means of output gap changes. The authors indicated the existence of a fiscal dominance regime in Brazil, as monetary policy was regarded as a passive policy, while the fiscal one was considered as an active policy, following the terminology of Leeper (1991).

In sequence, another empirical work, which investigated the nature of the monetary and fiscal interaction in Brazil, was Gadelha and Divino (2008). Using a long-run analysis, as well as bivariate and multivariate Granger causality tests, the evidence was supportive of a monetary dominance regime, according to Sargent and Wallace (1981). This result was based on the unidirectional causality from the Selic rate to the public debt, thus indicating an autonomous Central Bank. In addition, Gadelha and Divino (op. cit.) found results according to which primary surpluses changes were followed by impacts on the public debt over time. In their view, it was consistent with a potential public debt stabilization through a better primary surpluses management, then diverging from the concept of fiscal dominance pointed out by Blanchard (2004).

Araújo and Besarria (2014) also pointed to a monetary dominance regime in Brazil, by covering the sample from 2003 to 2009. They also rejected the hypothesis of Blanchard (2004) applied to Brazil, as their findings showed that a rise in the Selic rate was not accompanied by statistically significant changes in the sovereign risk premium, so that monetary policy maintained its effectiveness in shaping inflation rate by means of the covered parity theory, i.e., through the effects of interest rates on the exchange rate.

At last, Nobrega et al. (2020) applied a Markov-Switching VAR model (MS-VAR) in order to investigate the dominance regime (monetary or fiscal) in Brazil over the period from 2003 to 2015. Their benchmark results demonstrated the existence of a monetary dominance over the entire sample, when the estimates were based on a linear VAR. On the other hand, when they controlled for potential structural breaks through a MS-VAR approach, the empirical findings showed a statistically different regime in Brazil since 2011. From this year forward, they found that the money supply (M1) was adjusted so as to ease the stabilization of the public debt, which is consistent with a passive monetary policy over that second sub-sample. In sum, Nobrega et al. (op. cit.) found two different dominance regimes over the sample. In the first period, from 2003 to 2010, there was a monetary dominance regime, with a ricardian fiscal policy and an active monetary policy; since 2011, in contrast, there was a fiscal dominance regime, or a non-ricardian fiscal policy along with a passive monetary policy.

This implicit recent deterioration of the fiscal dynamics in Brazil is corroborated by other empirical studies, although through a different approach. These works aimed at investigating the nature of the fiscal rule and thus if the Brazilian public debt could be regarded as sustainable in long-term. Specifically, Moreira (2017) and Campos and Cysne (2019) found evidence for a pro-cyclical fiscal policy, mainly since the years around 2011, then confirming a loss of responsiveness of the primary surplus to the public debt path.

\section{Statistical Methodology and Data}

\subsection{Fractional Integration}

In the most part of the empirical studies regarding fiscal and monetary interactions, we find the application of conventional unit root or stationarity tests (such as ADF, PP and KPSS) in order to identify the integration order of the time series. Thus, these works do not verify the existence of long-memory or long-range dependence in data. It leads the resulting multivariate analysis to potential misestimation of relevant parameters. For instance, if one assumes a particular times series to be stationary based on conventional tests, but it in fact presents long-memory, then a resulting multivariate inference can overestimate reported coefficients.

Related empirical studies concerning fiscal and monetary aspects in Brazil commonly adopt typical Dickey-Fuller tests to identify unit root in data. However, according to Diebold and Rudebush (1991), it is well known that these procedures can over-(or under)estimate the integration order of the time series. It means that traditional tests like ADF, PP and KPSS are not able to deal with long-memory or dependence in data. For instance, Lee and Amsler (1997) pointed out that the KPSS test is not able to distinguish a process with nonstationary long memory $(0.5 \leq d<1)$ from an unit root process $(d=1)$, where $d$ stands for the fractional integration order.

A time series can present one of the following paths, regarding to the long-range dependency parameter $d:$ i) 
when $d=0$, we say that it has short-memory; when $0<d<0,5$, the time series is stationary with long-memory and mean reversion; when $0,5 \leq d<1$, it is nonstationary with long-memory, but it still shows mean reversion; and when, $d \geq 1$, we say it is nonstationary and does not present mean reversion. Furthermore, the intermediate memory (anti-persistence) case is defined when $d$ is in $[-0,5 ; 0)$.

So as to overcome the aforementioned weakness of the conventional tests in dealing with fractionally integrated time series, we adopted the fractional integration approach, based on method of Geweke and Porter-Hudak (GPH) (1983), which is robust to controlling and filtering the long-memory time series (Baillie et al., 1996; Wei, 2006).

Specifically, previously to our multivariate analysis based on the SVAR approach, we filtered the long-memory component of the data, by means of the estimated fractionally integrated parameter $(\hat{d})$. For this, the filter $(1-$ $B)^{\hat{d}_{i}} X_{t, i}$ was then adopted, where $i$ representing each time series $X_{t, i}$ and $B$ is the backward shift operator. Estimates of the fractionally parameter were made considering $g(n)=n^{0.5}$, where $g($.$) is the bandwidth and$ $n$ he number of observations (see Reisen, 1994).

\subsection{SVAR Models}

A Structural Vector Autoregressive model can be considered as an approach to deal with the identification problem in macroeconomics and monetary economics (Sims, 1980). By imposing recursive restrictions on the unexpected changes in the endogenous variables of a model, the SVAR method allows for a "shock view", i.e., it focus on the unexpected change of a specific variable in response to a shock in itself and to an unexpected change in other variables. As SVAR separates expected and unexpected changes in the endogenous variables it has an important difference from the conventional simultaneous equation models (Gottschalk, 2001). A reduced form of a SVAR model can be.

$$
Y_{t}=\Gamma^{-1} B(L) Y_{t}+\Gamma^{-1} e_{t}
$$

Where $Y_{t}$ is a vector of endogenous variables (e.g., those in our equation 1), $\Gamma^{-1}$ is an inverse matrix of contemporaneous parameters $(\Gamma), B(L)$ indicates the matrix of lagged parameters and $e_{t}$ yields the matrix of variance-covariance of innovations. Making $B^{*}=\Gamma^{-1} B$ and $u_{t}=\Gamma^{-1} e_{t}$ we can express.

$$
Y_{t}=B^{*}(L) Y_{t}+u_{t}
$$

The identifying restrictions in the SVAR approach assume that the structural innovations are orthogonal. It means that the covariance between two shock variances is restricted to zero. Besides, the SVAR analysis imposes a normalization on those variances, so that each of them becomes unitary. By doing so, we can interpret impulse response functions as the response of the economy to unit innovations, thereby resulting in $\Sigma_{e}=\left(\begin{array}{ll}1 & 0 \\ 0 & 1\end{array}\right)=I$, for the case of a bivariate model.

In turn, the identification, or causality order of the model, can be made by imposing an exclusion restriction on $\Gamma$. There exist other types of restrictions, such as non-recursive, long-run restrictions (Blanchard \& Quah, 1989), or a combination between contemporaneous and long-run restrictions (Gali, 1992). In our current econometric handling, the exclusion restriction on $\Gamma$ was adopted so as to impose contemporaneous causality relationships among the unexpected changes in the variables of the model.

Just for illustration, let the small system be composed by two variables $y_{1 t}$ and $y_{2 t}$. So, if we assume that a unit structural innovation to $y_{1 t}$ is not translated into an unexpected change of $y_{2 t}\left(\delta_{1,2}=0\right)$, then a $\Gamma$ matrix can be expressed as

$$
\Gamma=\left(\begin{array}{cc}
1 & \delta_{2,1} \\
0 & 1
\end{array}\right)
$$

In other words, we established an exogeneity condition on the model (i.e., $y_{2}$ is contemporaneously exogenous and $y_{1}$ is endogenous), so that an innovation $e_{2 t}>0$ causes unexpected changes in $y_{2 t}\left(u_{2 t}>0\right)$ and also in $y_{1 t}$ (which is signaled by the contemporaneous parameter $\delta_{2,1}$ to be estimated). It is noteworthy that one should build this type of identification constraint on theoretical and/or empirical foundations. In terms of our empirical aim, if we regard the fiscal primary surplus ( $p s)$ as an exogenous variable in relation to the others, due to political idiosyncrasies and/or legislative rigidities (an active fiscal policy according to Leeper, 1991), so we will designate the group of $\delta_{y_{i}, p s}=0$ in the $\Gamma$ matrix, thereby indicating that structural innovations $e_{i t}$ across $i$-variables do not create unexpected changes in $p s_{t}$.

\subsection{Data}

We used the following monthly time series encompassing the period from Jan-2004 to Apr-2019. In order to 
assess the fiscal policy main instrument, we adopted the series of the Brazilian public sector`s primary surplus ratio to GDP (\%) accumulated in the last 12 months $(p s)$; the general government's gross debt ratio to GDP $(\%)$ (debt); the consumer inflation rate accumulated in the last 12 months (\%), based on the Broad Consumer Prices Index $(p)$; and the real basic interest rate $(\%)$ in annual basis $(r)$, which was calculated by the difference between the effective nominal Selic rate and the accumulated expected inflation for 12 months forward. All these series are consistent with our intertemporal budget constraint (equation 1), and they were collected from Brazil's Central Bank data basis (www.bcb.gov.br). The graphical behavior of the data can be seen in Figure 1.

PS

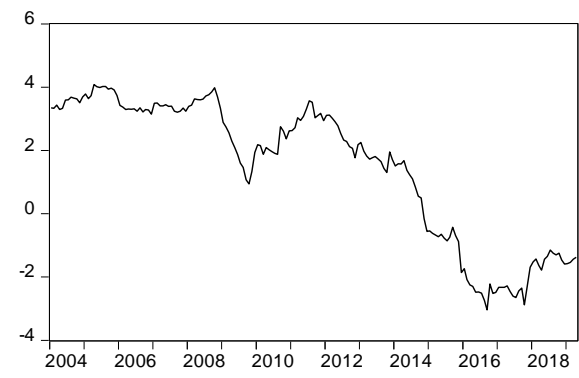

R

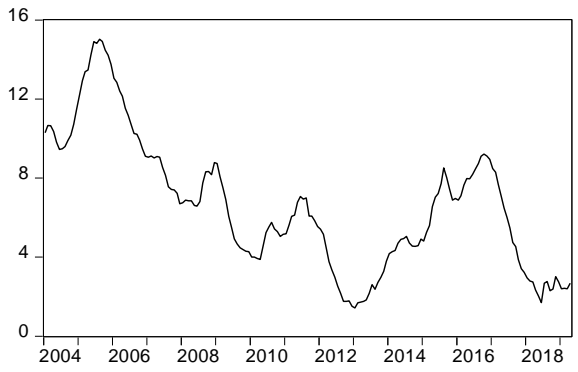

DEBT

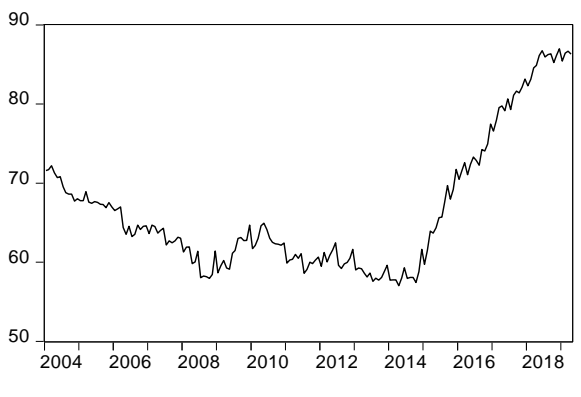

P

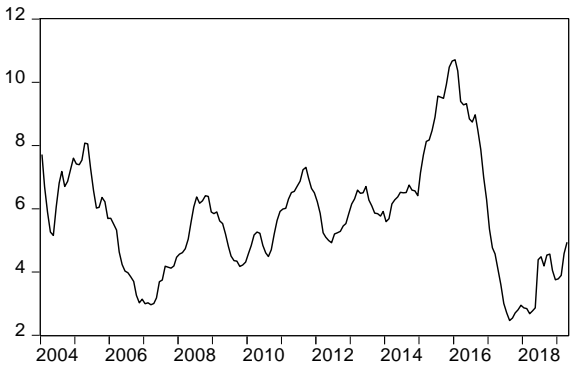

Figure 1. Time series from Jan-2004 to Apr-2019.

Source: drawn from the survey data.

\section{Analysis of Results}

\subsection{Application of the GPH Method and Filtered Time Series}

The first step of our estimation strategy was to extract the short-memory time series by means of the GPH method. Table 1 presents all the fractional integration order $\left(\hat{d}_{i}\right)$ of the time series. Once we identified all the series were marked by a long-memory component $(\hat{d}>0)$, we then extracted the respective short-memory series with the filter $(1-B)^{\hat{d}_{i}} X_{t, i}$, following Reisen (1994). It is noteworthy that $p s$ and debt showed a stochastic process with non-stationarity and without mean reversion $(\hat{d}>1)$, thereby indicating that Brazil's fiscal variables present extreme persistence over time, so that the application of conventional unit root tests and first-difference transformations could lead one to spurious estimates.

Table 1. Estimated GPH $(\hat{d})$ for the time series.

\begin{tabular}{ccc}
\hline Variable & GPH & Std-error \\
\hline$d e b t$ & 1.484 & 0.242 \\
$p s$ & 1.042 & 0.112 \\
$p$ & 0.398 & 0.199 \\
$r$ & 0.810 & 0.200 \\
\hline
\end{tabular}

Source: drawn from the survey data.

In the Appendix, we can observe the Graphical behavior after filtering our data, i.e., after extracting the long-memory component.

\subsection{SVAR Estimation}

In order to perform our first SVAR estimation, we preliminary disregarded the series of expected primary surplus 
(exp_ps). An important step was to identify the optimal lag of the model, so that we adopted AIC, SIC and HQ criteria (Table 2). These tests pointed to a 01-lag model, which was consistent with a stable parameter structure by means of the inverse roots of AR characteristic polynomial (Figure 2). In order to identify the exclusion restrictions on the $\Gamma$ matrix, we considered a regime of an active fiscal policy, in which the primary surpluses ( $p s)$ are exogenous (or pro-cyclical) to the public debt dynamics (in accordance with Campos \& Cysne, 2019 and Moreira, 2017). It is also in consistency with the fact of $\hat{d}>1$ for our fiscal variables, pointing to their high persistence (see Table 1).

Table 2. Optimal lag structure

\begin{tabular}{cccc}
\hline Lag & AIC & SIC & HQ \\
\hline 1 & 3.178 & $3.461^{*}$ & $3.293^{*}$ \\
2 & $3.108^{*}$ & 3.676 & 3.338 \\
3 & 3.185 & 4.036 & 3.530 \\
4 & 3.259 & 4.394 & 3.719 \\
\hline
\end{tabular}

Note. * indicates the optimal choice. Source: drawn from the survey data.

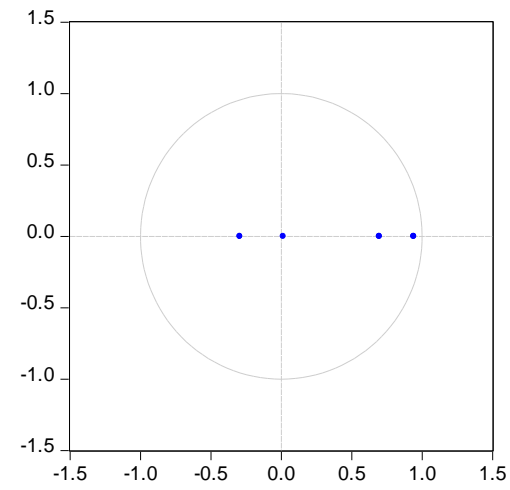

Figure 2. Inverse roots of AR characteristic polynomial

Source: drawn from the survey data.

In other words, shocks to the other variables do not have contemporaneous impact on $p s$. Such a non-ricardian regime, in turn, means that fiscal policy innovations $\left(e_{p s}\right)$ are followed by a public debt surprise, as well as conditioning unanticipated reactions in monetary policy (even if we assume that the Central Bank is attached to an inflation target regime, i.e., an active monetary policy). Besides, we do not regard the inflation dynamics as strictly rigid (or exogenous) in our estimation. On the contrary, we modeled it as an endogenous variable, so that unexpected changes in $p$ are contemporaneously induced by innovations to the other variables. These assumptions led to the following $\Gamma$ matrix,

$$
\Gamma=\left(\begin{array}{cccc}
1 & 0 & 0 & 0 \\
\delta_{p s, d e b t} & 1 & 0 & 0 \\
\delta_{p s, r} & \delta_{\text {debt }, r} & 1 & 0 \\
\delta_{p s, p} & \delta_{\text {debt }, p} & \delta_{r, p} & 1
\end{array}\right)
$$

For instance, at the first row and second column $\delta_{\text {debt,ps }}$ stands for 0 , thereby meaning that an unanticipated change of debt does not have effects on ps. Similarly, at the third row and fourth column, $\delta_{p, r}$ assumes 0 , expressing that the Central Bank (and so $r$ ) is not able to react contemporaneously to an innovation to the inflation dynamics $p$. The real interest rate is measured by the difference between nominal Selic rate and the expected inflation rate. If we take into account an inflation targeting regime in which monetary policy is credible and the expected inflation rate is not strongly sensitive to current inflation changes, so a shock to the latter will not be accompanied by contemporaneous movements in real interest rate.

The estimation of the structural factorization was performed with the maximum likelihood via Newton-Raphson (or analytic derivatives), so that our SVAR model was just-identified. Thus, the next step was to estimating impulse-response functions based on the structural decomposition method. As our main goal was to infer on the 
effects of monetary policy innovations on the unanticipated inflation dynamics, as well as on unexpected primary surpluses changes over time, Figure 3 brings the lagged responses of $p s$, debt and $p$ to structural innovations in $r$.

Let us initially consider the effect of a real interest rate innovation on the inflation rate. The response of $p$ to $r$ is below the predicted normal value until nearly the sixth month after the innovation (conditional to the statistical significance interval). In other words, when real interest rates increase unexpectedly, we observe an unanticipated reduction of the current inflation rate over around a half-year term. This finding is in accordance with the predicted effectiveness of monetary policy in shaping inflation rate over time.

In turn, let us focus on the response of primary surpluses $p s$ to a real interest rate innovation. When the Brazilian economy is under an unexpected rise in real interest rate there exists an unanticipated increment of $p s$ until around six months ahead. As we argued previously, such a result is non-conventional, and it can be explained based on the FTPL. As we assume that inflation rate is flexible to $r$ innovations, and besides fiscal policy is rigid to public debt changes, then an increment in $r$ is followed by a wealth effect as the decline in inflation rates causes a soaring public debt in real terms. As a consequence, current primary surpluses also increase by means of output and tax revenues higher levels. Therefore, an unexpected tighter monetary policy induces an unanticipated better fiscal result over around a half-year horizon.
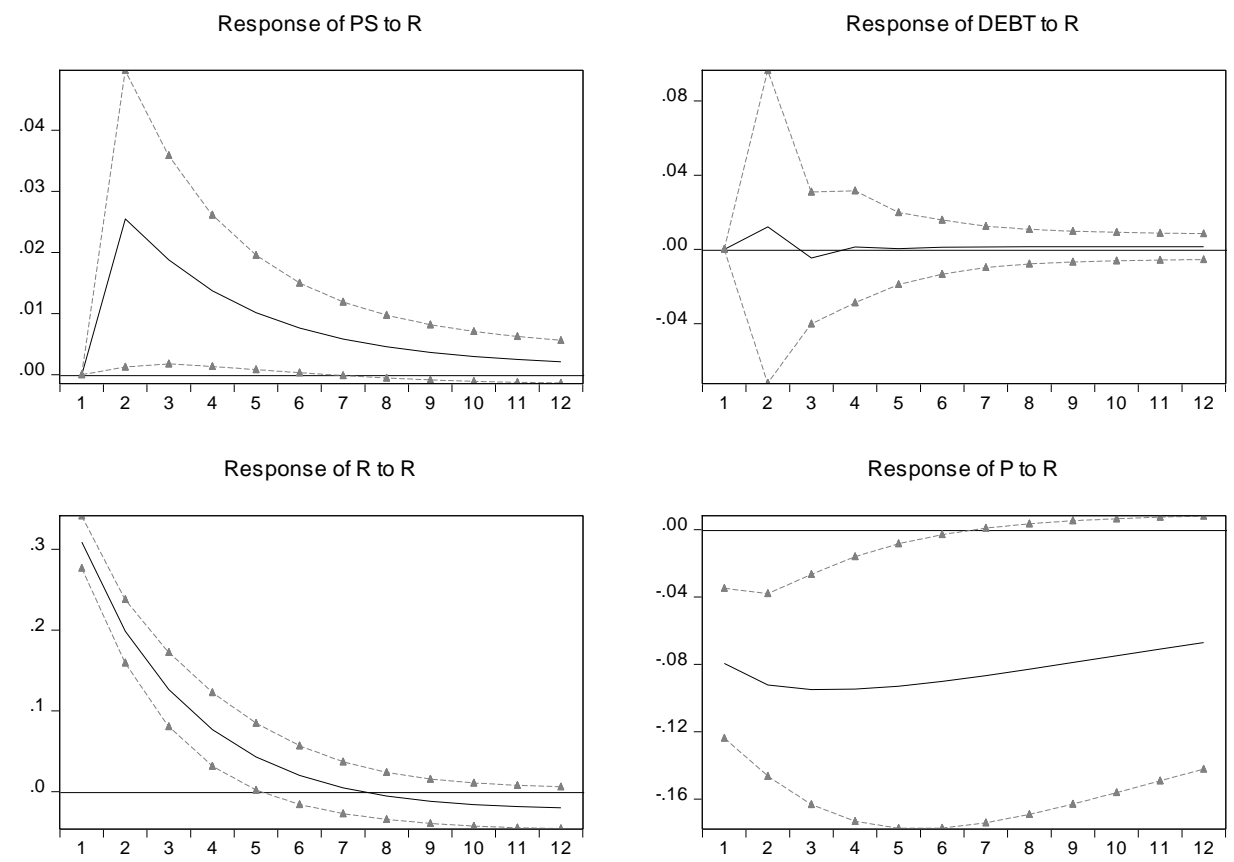

Figure 3. Unexpected responses to structural innovations in $r$

Source: drawn from the survey data.

\subsection{A robustness Checking: A Calibrated SVAR}

We proceeded with the analysis of robustness of the previously estimates by means of a calibrated SVAR model. The unique difference in relation to the previous model was the imposition of constraints on $B(L)$, which indicates the matrix of lagged parameters in equation (2).

We calibrated the following restrictions based on empirical evidence for the Brazilian economy. With regard to Campos and Cysne (2019), we assumed that the primary surplus responds to the lagged public debt change, although in a weak magnitude $\left(0.05\right.$ for $\left.b_{\text {debt-1,ps }}\right)$. This evidence is consistent with other works pointing to a pro-cyclical fiscal policy path in Brazil, such as Moreira (2017). In turn, we allowed for an inertial inflationary component ( 0.8 for $\left.b_{p t-1, p}\right)$, i.e., an effect of the lagged inflation rate on the current level. Such a parameter was built on the findings of Moreira et al. (2018). At last, we also included a smoothing component into the interest rate dynamics, following the adopted central value $\left(0.9\right.$ for $\left.b_{r t-1, r}\right)$ in the structural model of the Brazilian Central Bank (Central Bank of Brazil, 2020). Therefore, additionally to (5), we restricted the $B(L)$ matrix to, 


$$
B(L)=\left(\begin{array}{cccc}
b_{p s-1, p s} & 0.05 & b_{r-1, p s} & b_{p-1, p s} \\
b_{p s-1, \text { debt }} & b_{\text {debt-1,debt }} & b_{r-1, \text { debt }} & b_{p-1, \text { debt }} \\
b_{p s-1, r} & b_{\text {debt }-1, r} & 0.9 & b_{p-1, r} \\
b_{p s-1, p} & b_{\text {debt }-1, p} & b_{r-1, p} & 0.8
\end{array}\right)
$$

Again, the estimation of the structural factorization was handled by the maximum likelihood via Newton-Raphson (or analytic derivatives), so that our SVAR model was just-identified. Figure 4 shows the impulse-response functions based on the structural decomposition method.

We can observe that the previously main evidence is supported by our alternative estimation. The differences are related to the duration of the responses and their peak levels. For instance, in the alternative estimation (calibrated SVAR), the positive shock to the real interest rate is followed by an unanticipated inflation drop which endures only 01 month after the innovation, against nearly 06 months of duration in the previous estimation.

In turn, the unexpected response of primary surpluses to an innovation to $r$ maintained the aforementioned direction. When the Central Bank tightens monetary policy there exists an unpredicted rise in primary surpluses, which lasts for about 06 months, similarly to the previous benchmark estimation. The slightly difference is only in terms of the peak level magnitude, which attains around 0.036 in the calibrated estimation, in comparison to 0.025 in the benchmark SVAR. Overall, we can stress that our main evidence is corroborated when we take into account some empirical structural values regarding lagged relations in Brazil.

Response of PS to R

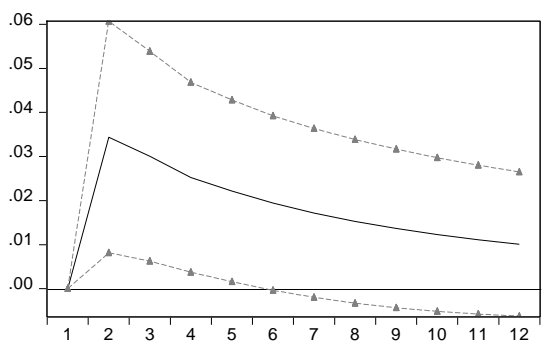

Response of $\mathrm{R}$ to $\mathrm{R}$

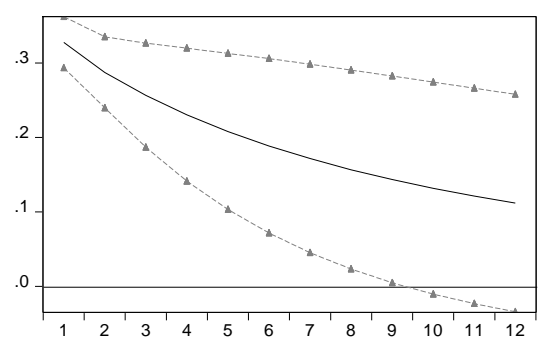

Response of DEBT to $R$
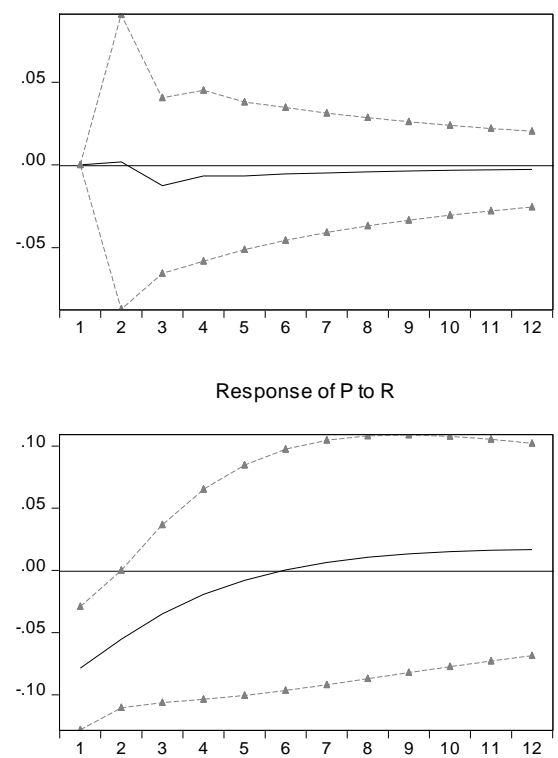

Figure 4. Unexpected responses to structural innovations in $r$ (Calibrated SVAR)

Source: drawn from the survey data.

\section{Concluding Remarks}

In this work we aimed at investigating the nature of the interaction between monetary and fiscal policies in Brazil. From a theoretical aspect, we built on the concepts of dominance regimes, intertemporal budget constraints and a potential wealth channel from the public debt dynamics. Such a view is based on the Fiscal Theory of the Price Level.

Several works have studied fiscal and monetary policy rules for the Brazilian economy, and some of them have achieved results indicating an active fiscal policy (i.e., a pro-cyclical one), besides an inflation target-committed monetary policy (i.e., a counter-cyclical one). According to the FTPL, such a scheme can be accompanied by inflationary pressures, so that the Central Bank stays under the risk of losing its effectiveness to control inflation.

Alternatively, we found a particular effect of real interest rate innovations in Brazil, which can be explained with the FTPL. Through Structural VAR models, we estimated the unpredicted response of inflation rates and primary surpluses to monetary policy shocks, from Jan/2004 to Apr/2019. Besides, we did not build our analysis on 
conventional unit root tests. We rather performed a fractional integration approach, thereby filtering out the times series' long-memory component.

Our main evidence can be summarized in two topics: a) we confirmed the role and effectiveness of the monetary policy innovation in affecting inflation rate. An unanticipated tighter monetary policy is followed by an unforeseen decline in inflation which remains around 01 to 06 months below its normal or predicted level; b) the real interest rate shock is accompanied by an unpredicted increment of the primary surplus. This unconventional result can be explained by taking into account the wealth effect into the FTPL. As the fiscal policy does not correct itself facing a public debt change, when the real interest rate increases (and the inflation rate declines as a consequence) there exists a rise in real public debt. In a context in which households continue to hold public bonds due to non-default risks, these assumptions mean that the intertemporal budget constraint should be satisfied by a rise in primary surpluses. It occurs by the wealth channel: an increment of real public debt is regarded as an unforeseen expansion of private savings, thereby inducing higher consumption and output levels, and so a resulting soaring primary surplus via tax revenues.

In terms of fiscal and monetary policy interactions in Brazil, our study found that the Central Bank was a leader to shape inflation, as well as to stimulate better fiscal outcomes over the time sample, by means of a type of disciplinary effect. Although it is more plausible that the unanticipated enlargement of the primary surplus (as an effect of a real interest rate shock) was induced by higher tax revenues, we can assume that a tight monetary policy stimulates a better management of public expenses, so that it would work as a dominant force to avoid the continuity of a pro-cyclical fiscal policy in long-term. In sum, the evidence achieved in this work is more consistent with the assumption of a monetary dominance regime in Brazil, even if we take into account that the fiscal policy does not present an appropriate responsiveness to the public debt path over the time sample.

\section{References}

Araujo, J. M., \& Besarria, C. (2014). Dominance relationship between fiscal and monetary policy: An analysis for Brazilian economy in the period 2003-2009. Revista de Economia, 40(1), 55-70. https://doi.org/10.5380/re.v40i1.30524

Baillie, R. T., Chung, C. F., \& Tieslau, M. A. (1996). Analysing inflation by the fractionally integrated ARFIMA-GARCH model. Journal of Applied Econometrics, 11(1), 23-40. https://doi.org/10.1002/(SICI)1099-1255(199601)11:1<23::AID-JAE374>3.0.CO;2-M

Blanchard, O. (2004). Fiscal dominance and inflation targeting: lesson from Brazil. NBER Working Papers, $\mathrm{n}$. 10389. https://doi.org/10.3386/w10389

Blanchard, O. J., \& Quah, D. T. (1989). The Dynamic Effects of Aggregate Demand and Supply Disturbances. The American Economic Review, 79(4), 655-673. https://doi.org/10.3386/w2737

Campos, E. L., \& Cysne, R. P. (2019). A Time-Varying Fiscal Reaction Function for Brazil. Estudos Econômicos, 49(1), 5-38. https://doi.org/10.1590/0101-41614911ecr

Central Bank of Brazil. (2020). Inflation Report. December/2020.

Cochrane, J. H. (1998). A Frictionless View of U.S. Inflation. NBER Macroeconomics Annual, 13, 323-84. https://doi.org/10.1086/ma.13.4623752

Diebold, F. X., \& Rudebush, G. D. (1991). On the power of Dickey-Fuller tests against fractional alternatives. Economics Letters, 35(2), 155-160. https://doi.org/10.1016/0165-1765(91)90163-F

Fialho, M. L., \& Portugal, M. S. (2005). Monetary and fiscal policy interactions in Brazil: An application of the fiscal theory of the price level. Estudos Econômicos, 35(4), 657-685. https://doi.org/10.1590/S0101-41612005000400003

Gadelha, S. R., \& Divino, J. A. (2008). Dominância fiscal ou dominância monetária no Brasil? Uma análise de causalidade. Economia Aplicada, 12(4), 659-675. https://doi.org/10.1590/S1413-80502008000400006

Gali, J. (1992). How Well Does the IS-LM Model Fit Postwar US Data?. Quarterly Journal of Economics, 107(2), 709-738. https://doi.org/10.2307/2118487

Geweke, J., \& Porter-Hudak, S. (1993). The estimation and application of long memory time series models. Journal of Time Series Analysis, 4(4), 221-238. https://doi.org/10.1111/j.1467-9892.1983.tb00371.x

Gottschalk, J. (2001). An introduction into SVAR methodology: Identification, interpretation and limitations of SVAR models. Kiel Working Paper, n.1072.

Kydland, F. E., \& Prescott, E. C. (1977). Rules Rather than Discretion: The Inconsistency of Optimal Plans. 
Journal of Political Economic, 85(3), 473-492. https://doi.org/10.1086/260580

Lee, H. S., \& Amsler, C. (1997). Consistency of the KPSS unit root test against fractionally integrated alternative. Economics Letters, 55(2), 151-160. https://doi.org/10.1016/S0165-1765(97)00066-9

Leeper, E. M. (1991). Equilibria under 'active' and 'passive' monetary and fiscal policies. Journal of Monetary Economics, 27(1), 129-147. https://doi.org/10.1016/0304-3932(91)90007-B

Moreira, R. R. (2017). Pro-cyclical fiscal policy in Brazil: long- and short-term relationships using cointegration and error correction model (2005-2015). International Journal of Economic Policy in Emerging Economies, 10(2), 171-184. https://doi.org/10.1504/IJEPEE.2017.085287

Moreira, R. R., Monte, E. Z., \& Abdala, A. (2018). Inflation targeting and inflation deviation inertia: A study for Brazil based on the fractional integration approach. Journal of Applied Economics, 21(1), 67-83. https://doi.org/10.1080/15140326.2018.1526877

Moreira, T. S., Souza, G. S., \& Almeida, C. L. (2007). The Fiscal Theory of the Price Level and the Interaction of Monetary and Fiscal Policies: The Brazilian Case. Revista Brasileira de Econometria, 27(1), 86-106. https://doi.org/10.12660/bre.v27n12007.1573

Nobrega, W. C. L., Maia, S. F., \& Besarria, C. D. N. (2020). Interação entre as Políticas Fiscal e Monetária: Uma Análise sobre o Regime de Dominância Vigente na Economia Brasileira. Análise Econômica, 37(4), 7-34. https://doi.org/10.22456/2176-5456.71935

Reisen, V. A. (1994). Estimation of the fractional difference parameter in the ARIMA(p, d, q) model using the smoothed periodogram. Journal of Time Series Analysis, 15(3), 335-350. https://doi.org/10.1111/j.1467-9892.1994.tb00198.x

Sargent, T., \& Wallace, N. (1981). Some unpleasant monetarist arithmetic. Quarterly Review, 5(3), 1-19. https://doi.org/10.21034/qr.531

Sims, C. A. (1980). Macroeconomics and Reality. Econometrica, 48(1), 1-48. https://doi.org/10.2307/1912017

Woodford, M. (2001). Fiscal requirements for price stability. Journal of Money, Credit and Banking, 33(3), 669-728. https://doi.org/10.2307/2673890

\section{Appendix}
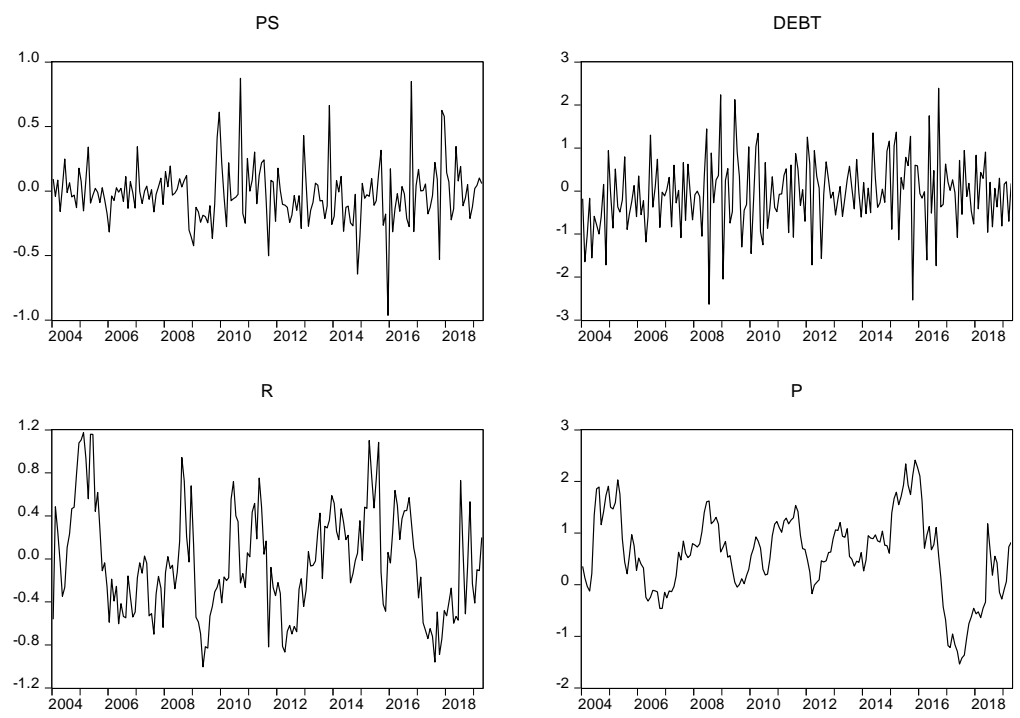

Figure A. Filtered (short-memory) time series from Jan-2004 to Apr-2019

Source: drawn from the survey data.

\section{Copyrights}

Copyright for this article is retained by the author(s), with first publication rights granted to the journal.

This is an open-access article distributed under the terms and conditions of the Creative Commons Attribution license (http://creativecommons.org/licenses/by/4.0/). 